Consumer Participation in Co-creation: Investigating the

Reem Refai Ahmed Mahmoud

\title{
Consumer Participation in Co-creation: Investigating the Moderating Role of Empathy
}

\section{Reem Refai Ahmed Mahmoud}

\section{Abstract}

The current study explores one of the boundary conditions under which customers decide to engage in cocreation activities which is empathy. A sample of 103 participants were recruited and between-subjects experimental design with two groups (treatment vs. control) were employed. Hayes PROCESS model 1 were utilized for data analyses. The finding did not provide support for any of the empathy subscales as a moderator of the link between cocreation and both behavioral intentions and word of mouth communication intentions. Thus, regardless of the level of empathetic orientation an individual co-creation produces a positively strong direct impact on both behavioral intentions and word of mouth communication intentions. Future research should consider testing this link using different types of cocreation (e.g., co-creation for others) to provide deeper understanding on the role of empathy. 
Consumer Participation in Co-creation: Investigating the

Reem Refai Ahmed Mahmoud

\section{Introduction}

The new millennium witnessed a rapid change in consumer behavior accelerated by the massive progress in information and communication technologies. This change of how consumers behave led to a corresponding change in the way businesses and consumers interact. Consumers now are more informed and connected with other consumers and business organizations. This change places great challenges on business organizations to cope with this new pattern of consumer behavior, they begin to involve their consumers in every step of their product and service offerings believing that this is the way to excel in competition and to retain their customers and their position in the market place. This new orientation is known as "co-creation of value".

\section{The definition of co-creation}

Despite the increasing importance of co-creation as an approach to utilize customer competences (Kambil et al., 1996; Prahalad and Ramaswamy, 2004; and Edvardsson et al., 2010), there is a limited consensus on its exact definition. This is presumably attributed in part to the fact that this area of research is in its infancy (Hoyer et al., 2010 and Roberts et al., 2014). In addition, the notion of co-creation overlaps with similar concepts such as co-production, crowdsourcing, mass 
Consumer Participation in Co-creation: Investigating the

Reem Refai Ahmed Mahmoud

customization, and open innovation. It also may be due to its wide applications context, which makes it more challenging to specify a clear-cut definition of co-creation. Table 1 below provides some of the co-creation definitions presented in the literature.

\section{Table 1 Definitions of Co-Creation in Literatue}

Author

\begin{tabular}{|c|c|}
\hline $\begin{array}{l}\text { Ramaswamy \& } \\
\text { Gouillart } \\
\text { (2010) }\end{array}$ & $\begin{array}{l}\text { "[...] as the "practice of developing systems, products or } \\
\text { services through collaboration with customers, managers, } \\
\text { employees, and other company's stakeholders" } \\
\text { (Ramaswamy \& Gouillart, 2010, P.4). It is neither the } \\
\text { transfer nor the outsourcing of activities to customers or } \\
\text { a marginal customization of products and services. Nor it } \\
\text { is a scripting or staging of customer events around the } \\
\text { firm's various offering (Prahalad and Ramaswamy 2004, } \\
\text { P.16) }\end{array}$ \\
\hline Zwas & $\begin{array}{l}\text { "[...] as "the participation of consumers along with } \\
\text { producers in the creation of value in the marketplace" } \\
\text { (P.13). }\end{array}$ \\
\hline $\begin{array}{l}\text { Gustafsson et } \\
\text { al. (2012) }\end{array}$ & $\begin{array}{l}\text { "[...] as "a frequent, bidirectional, and face-to-face } \\
\text { communication process that is used when attempting } \\
\text { creative problem solving" (P.11). }\end{array}$ \\
\hline
\end{tabular}

\section{Definition}

Typology of co-creation 
Consumer Participation in Co-creation: Investigating the

Reem Refai Ahmed Mahmoud

In 2010, Zwass made an interesting effort to make a taxonomy of co-creation. He classified it into sponsored cocreation such of this of Procter \& Gamble and IBM, autonomous co-creation as Wikipedia, and combination of both like the Polyvore e-commerce site. Sponsored co-creation comprises "co-creation activities conducted by consumer communities or by individuals at the behest of an organization (termed the producer)". In autonomous co-creation, individuals or consumer communities produce marketable value in voluntary activities conducted independently of any established organization, although they may be using platforms provided by such organizations, which benefit them economically (Zwass, 2010, P.11).

Witell et al (2011) noted that a distinction between cocreation for use and co-creation for value-exchange, cocreation for others, is ultimately needed. Co-creation for use is typically performed by a specific customer for his or her own benefit, whereas co-creation for others is performed in favor of other customers. While the aim of co-creation for use is to enjoy the production process and its outcome, co-creation for others aims to provide an idea, share knowledge or participate in the development of a product or service that can be of value for other customers (Witell et al., 2011, P.143). 
Consumer Participation in Co-creation: Investigating the

Reem Refai Ahmed Mahmoud

\section{Research Questions and Objectives}

This research aims to provide a detailed investigation of the processes that shape consumers' decisions toward involvement in co-creation. We herein propose that empathy can play an important role in motivating consumers to engage in co-creation activities. This research aim is to answer our main research question stated below:

R.Q: Does Empathy Energize Consumers' Decisions Toward Involvement in Co-Creation?

\section{The Study in Context}

The present research tackles customers' co-creation experiences in the context of higher education institutions (HEI), mainly universities.

\section{Major Areas of Contributions}

Our intended contribution is to shed light on consumers' decisions toward involvement in co-creation. More specifically, the study attempts to explore the role of consumers' empathetic orientation in shaping their decision to engage in co-creation activities. Furthermore, the current study will test the proposed model in experimental setting, which provides more valid and reliable findings from which conclusions can be drawn. 
Consumer Participation in Co-creation: Investigating the

Reem Refai Ahmed Mahmoud

\section{Hypotheses Development and Conceptual Model}

Bagozzi and Moore (1994) defined empathy as "the heightened awareness of another person in danger or distress and include an urge to take action to alleviate the other person's plight" (P.59). The moderating role of empathy on decision-making and willingness to help has been investigated in a considerable number of studies. Bagozzi and Moore (1994) investigate the role of emotions and empathy on prosocial behavior in the context of public service ads. They indicated that exposure to public service ads directed at antichild abuse stimulates negative emotions (anger, sadness, fear and tension) leading to empathic responses influencing the decision to help. Rosenbaum and Massiah (2007) noted that customers usually recall difficulties that they encountered before and use it to form a strong sense of empathy and social responsibility to help other customers facing similar difficulties (Chuang and Chen, 2015). Bharti, Agrawal, and Sharma (2014) show that empathy is an important factor in influencing customers to participate in value co-creation activities. They argued that empathetic attitudes of consumers toward a cause or community might influence participation decisions. Thus, empathy can be considered an enabler for 
Consumer Participation in Co-creation: Investigating the

Reem Refai Ahmed Mahmoud

value co-creation. By applying this rationale to the context of participation in co-creation for others we hypothesize that:

H.1 (a) Consumer empathy moderates the relationship between level of involvement in co-creation and behavioral intentions.

H.2 (b) Consumer empathy moderates the relationship between level of involvement in co-creation and word-ofmouth intentions (WoM).

Figure 1 conceptual model

\section{MEASURES}

Manipulation of the Independent Variable

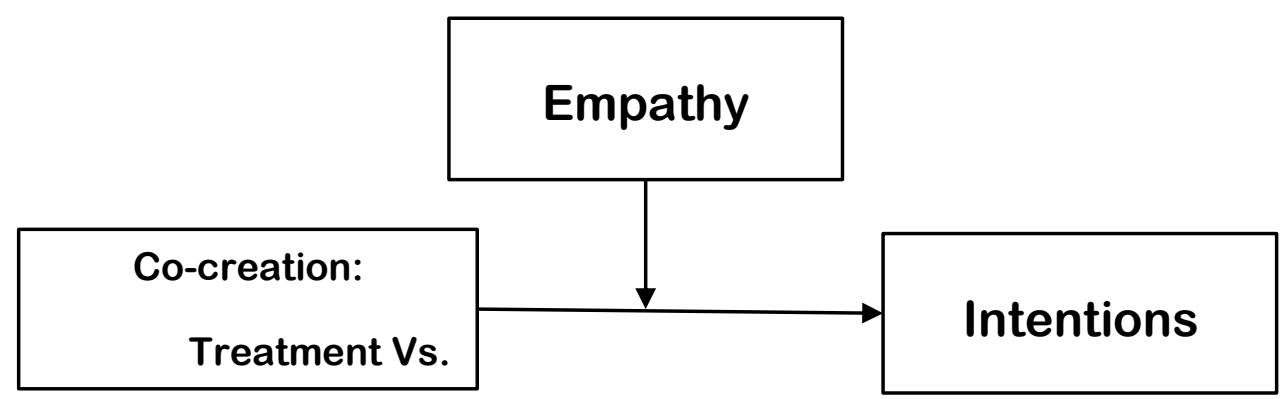

Co-creation was operationalized by means of scenario manipulation. Two scenarios/conditions were used, one experimental/treatment condition and one control condition. The treatment condition described co-creation activities taken 
Consumer Participation in Co-creation: Investigating the

Reem Refai Ahmed Mahmoud

place between the University of Michigan library and its students. Since our research context is the higher education market, the narrative scenarios described co-creation activities with this context (the university library and students). The scenarios adapted from Mahmoud (This Issue).

\section{Moderator Variable (W):}

Empathy was measured by using Bagozzi (2017) 10items scale which was adapted from (Davis 1980 and BaronCohen \& Wheelwright, 2004). The scale contains three subdimensions of empathy: perspective taking (putting oneself in the shoes of others), theory of mind (inferring the thoughts, feelings, intentions of others), and Empathetic concern (feeling the emotion of others, compassion). Respondents were asked to rate their thoughts and feelings regarding each statement using the following scale: 1 (does not describe me at all), 4 (describe me moderately well), and 7 (describes me very well).

\section{Outcome/Dependent Variables (Y):}

Two dependent variables were used to measure the effects of co-creation on consumers (in our case students).

Behavioral Intentions: Behavioral intentions were measured with the query: "As you watched the scenario, for 
Consumer Participation in Co-creation: Investigating the

Reem Refai Ahmed Mahmoud

each of the following statements, please indicate the likelihood that you, personally, would engage in the described activity or behavior in the future. Two items were

1) "If you were to plan for an educational trip in the future, you would collaborate with the university library to plan it as the one described in the video." (5-point "Very Unlikely-Very Likely" scale).

2) If you were given the opportunity to co-create (produce or design) an educational trip with the university Library, you would be inclined to avoid doing so." (5-point "strongly disagree- strongly agree" scale).

Word-of-Mouth (WoM) intentions: WoM intentions were measured with the query: "As you watched the scenario, for each of the following statements, please indicate the likelihood that you, personally, would engage in the described activity or behavior in the future. The two items were

1) "If your friends were to plan for an educational trip in the future, you would recommend them to collaborate with the University library to plan it as the one described in the scenario." (5-point "Definitely not recommend" Definitely recommend" scale).

2) "If your friends were to plan for an educational trip in the future, you would speak favorably about using the 
Consumer Participation in Co-creation: Investigating the

Reem Refai Ahmed Mahmoud

University library to plan it." (7-point "Very UnlikelyVery Likely" scale).

\section{Background and covariate variables:}

Socio-demographic factors: Socio-demographic factors including age, educational level, and marital status were recorded.

Familiarity: Participants were asked to answer the two following items using a scale from 0-6: 1) "to what extent are you familiar with the concept of co-creation?" 2) "How experienced are you with co-creation activities?"

Trust: Participants were asked to answer the two items using a scale from 0-6: 1) "express how much confidence you have that this brand (UMICH Library) will meet your needs, 2) "indicate to what degree you trust that this brand will meet your needs".

Involvement: Delgado-Ballester and Munuera-Alemán (2001) three 5-points semantic differential items were used: For you, please indicate how much the library services are (Unimportant-Important; Means nothing to me- Means a lot to me; Irrelevant-Relevant). 
Consumer Participation in Co-creation: Investigating the

Reem Refai Ahmed Mahmoud

\section{METHOD}

\section{Participants and design:}

Random sample of 166 participants was recruited from the Paid Subject Pool in the behavioral lab at the Ross School of Business. The research instruments are based on scenario manipulations and questionnaires. Between-subjects experimental design was employed with two treatments group (high co-creation condition vs. low co-creation) and a Control Group (No co-creation).

\section{Realism check:}

Realism of the scenario was mainly assessed by two inquiries via a seven-point Likert type scale adapted from Bagozzi and Dabholkar (1994). The two questions are: how realistic was the scenario description? and how difficult was it for you to project yourself into the scenario?

\section{Manipulation check:}

A manipulation check was conducted to verify whether the respondents understood the co-creation manipulations as intended or not. The efficacy of the manipulation on the independent variable was assessed by two questions based on 7-point Likert type scales are 1) Please indicate the degree of the University librarian and staff involvement/ engagement/ 
Consumer Participation in Co-creation: Investigating the

Reem Refai Ahmed Mahmoud

participation in planning and designing the trip, and 2) Please indicate the interaction level among the student and university librarian and staff in planning and designing the trip".

\section{Experimental Procedures}

Firstly, upon arrival to the behavioral lab each participant was asked to read and sign an IRB (Institutional Review Board) approved consent form. Each of the participants was randomly assigned to one of the experimental conditions. Secondly, Subjects were asked to answer individual differences scales. After that, participants were instructed to, watch an audio-visual presentation of a hypothetical scenario and try to vividly imagine themselves experiencing the situations provided. After exposure to the stimuli, each participant was asked to fill out a survey with dependent and other variables.

\section{RESULTS}

\section{Sample Description:}

Participants were recruited from the Paid Subject Pool in the behavioral lab of Ross Business School at the University of Michigan. A total of 166 Graduate 
Consumer Participation in Co-creation: Investigating the

Reem Refai Ahmed Mahmoud

and undergraduate students participated in the study, of which 141 provide valid responses. The final number of participants in each of these groups was 93 participants randomly assigned to one of the two treatment groups (55 in the High co-creation condition and 38 in the low). In addition, 48 participants were randomly assigned to the control group. A total of 25 surveys were considered not valid and discarded from the final sample. The decision to eliminate a survey from further analysis is based on either the speed of completing the survey and/or straightforward responses (responses with zero standard deviation).

\section{Results of Manipulation \& Realism check:}

Manipulation Check: A one way between groups ANOVA was conducted (after meeting the required assumptions). There were statistically significant differences between the 3 groups. Thus, the two experimental and the control treatments or manipulations appeared to have worked well.

Realism Check: Participants were asked about the realism of the scenario and whether they could imagine themselves in such a situation on a 7-point scale (0: unrealistic, 6: very realistic). A one sample t-test against the midpoint of 4 indicated that participants thought the scenario were realistic enough for the high condition and control group 
Consumer Participation in Co-creation: Investigating the

Reem Refai Ahmed Mahmoud

but not for the low condition for this reason, the low group was excluded from further analysis and the total sample reached 103 in the two remaining groups.

\section{Measurement model}

Factor analysis (EFA) was utilized as a means of data reduction. Items with cross loadings (>.25) and low factor loadings $(<.40)$ were eliminated. To assess scales reliability, the internal consistency of the remaining items on each factor (scale sub-dimension) was measured using Cronbach's Alpha. Alpha estimates for each subscale ranged from 0.64 to 0.7 . Thus, overall the measures achieved internal consistency according to acceptable cutoff values indicated in the literature.

\section{Hypotheses Testing}

To find an indication for the plausibility of using PROCESS moderation mediation models, several diagnostic procedures were followed. The dataset was tested for the basic regression assumptions (linearity, homoscedasticity, and normality). Then Identifying outliers in the data by checking the three distances indicators; Mahalanobis, Cook's, and Leverage values while running the liner multiple regression. Finally, a collinearity diagnoses was carried out. All the diagnostic procedures provided strong evidence in support for the plausibility of employing regression models for our

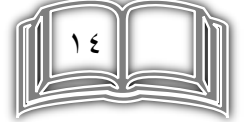


Consumer Participation in Co-creation: Investigating the

Reem Refai Ahmed Mahmoud

subsequent analyses, since none of the regression assumptions (i.e., normality, linearity, and homoscedasticity) were seriously violated.

Empathy then was tested as a simple moderator of the relation between co-creation and both behavioral intentions and word-of-mouth intentions using "Model 1" in Hayes PROCESS Macro. Trust, involvement and familiarity were entered into the PROCESS Macro as covariates. Behavioral intention was entered as the outcome variable (Y1). The two groups representing the co-creation manipulation were dummy coded (Treatment $=1 \&$ Control $=$ Zero $)$ and entered as the independent variable $(\mathrm{X})$ variable. The same steps were repeated using the study second dependent variable word-ofmouth intentions (WoM: $\mathrm{Y}_{2}$ ). A 10,000 bias corrected bootstrap sampling were requested and covariates in the model were entered as covariates of both $\mathrm{M}$ and $\mathrm{Y}$ variables.

\section{Empathy (EmpT: M1):}

The three sub-dimensions of the Empathy scale (perspective taking, theory of mind and empathetic concern) were tested for moderation effect separately. The parameters of the three sub-dimensions are graphically presented in figure 4.2 . 
Consumer Participation in Co-creation: Investigating the

Reem Refai Ahmed Mahmoud

Perspective taking (EmpPT): the overall model was significant $(\mathrm{F}(6,96)=16.37, \mathrm{p}<.001)$, accounting for $51 \%$ of the overall variance in behavioral intentions $\left(\mathrm{R}^{2}=.51\right.$, MSE $=1.04)$. However, the interaction (ManipHC X EmpPT) was not significant $(F(1,96)=.05, p=83)$. The $\mathrm{R}^{2}$ increase due to interaction $\left(\mathrm{R}^{2}\right.$-chng $\left.=.0002\right)$. That is, EmpPT was a nonsignificant moderator of the link between co-creation on behavioral intentions.

Regarding the model second outcome variable word-ofmouth intentions (WoM), again the overall model was significant $(\mathrm{F}(6,96)=27.04, \mathrm{p}<.001)$, accounting for $62 \%$ of the overall variance in word-of-mouth intentions $\left(\mathrm{R}^{2}=.63\right.$, $\mathrm{MSE}=1.7818$ ). However, the interaction (ManipHC $\mathrm{X}$ EmpPT) was non-significant $(F(1,96)=.02, p=88)$. The $\mathrm{R}^{2}$ increase due to interaction $\left(\mathrm{R}^{2}\right.$-chng $\left.=.0001\right)$. That is, EmpPT was a non-significant moderator of the link between cocreation on word-of-mouth intentions.

Theory of Mind (EmpToM): the overall model was significant $(\mathrm{F}(6,96)=16.25, \mathrm{p}<.001)$, accounting for $50.38 \%$ of the overall variance in behavioral intentions $\left(\mathrm{R}^{2}=\right.$ $.50, \mathrm{MSE}=1.05)$. However, the interaction (ManipHC X EmpToM) was not significant $(F(1,96)=.43, p=.51)$. The $\mathrm{R}^{2}$ increase due to interaction $\left(\mathrm{R}^{2}\right.$-chng $\left.=.0022\right)$. That is, 
Consumer Participation in Co-creation: Investigating the

Reem Refai Ahmed Mahmoud

EmpToM was a non-significant moderator of the link between co-creation on behavioral intentions.

Regarding the model second outcome variable word-ofmouth intentions (WoM), again the overall model was significant $(\mathrm{F}(6,96)=27.40, \mathrm{p}<.001)$, accounting for $63 \%$ of the overall variance in word-of-mouth intentions $\left(\mathrm{R}^{2}=.63\right.$, MSE =1.77). However, the interaction (ManipHC $X$ EmpToM) was not significant $(F(1,96)=.8072, p=.37)$. The $\mathrm{R}^{2}$ increase due to interaction $\left(\mathrm{R}^{2}\right.$-chng $\left.=.0031\right)$. That is, EmpToM was a non-significant moderator of the link between co-creation on word-of-mouth intentions.

Empathetic Concern (EmpCon): the overall model was significant $(\mathrm{F}(6,96)=17.38, \mathrm{p}<.001)$, accounting for $52 \%$ of the overall variance in behavioral intentions $\left(\mathrm{R}^{2}=.52\right.$, MSE $=1.01$ ). However, the interaction (ManipHC X EmpCon) was not significant $(F(1,96)=.2 .39, p=.13)$. The $\mathrm{R}^{2}$ increase due to interaction $\left(\mathrm{R}^{2}\right.$-chng =. 01). That is, EmpCon was a nonsignificant moderator of the link between co-creation on behavioral intentions.

Regarding the model second outcome variable word-ofmouth intentions (WoM), again the overall model was significant $(\mathrm{F}(6,96)=27.25, \mathrm{p}<.001)$, accounting for $63 \%$ of the overall variance in word-of-mouth intentions $\left(\mathrm{R}^{2}=.63\right.$, 
Consumer Participation in Co-creation: Investigating the

Reem Refai Ahmed Mahmoud

MSE = 1.77). However, the interaction (ManipHC $\mathrm{X}$ EmpCon) was non-significant $(F(1,96)=.59, p=.44)$. The $\mathrm{R}^{2}$ increase due to interaction $\left(\mathrm{R}^{2}\right.$-chng $\left.=.0023\right)$. That is, EmpCon was not a significant moderator of the link between co-creation on word-of-mouth intentions. 
Figure 2 Statistical Models for The Effect of Co-Creation Manipulation on Behavioral Outcomes (BI \& WoM) Through Each of the Empathy Subscales

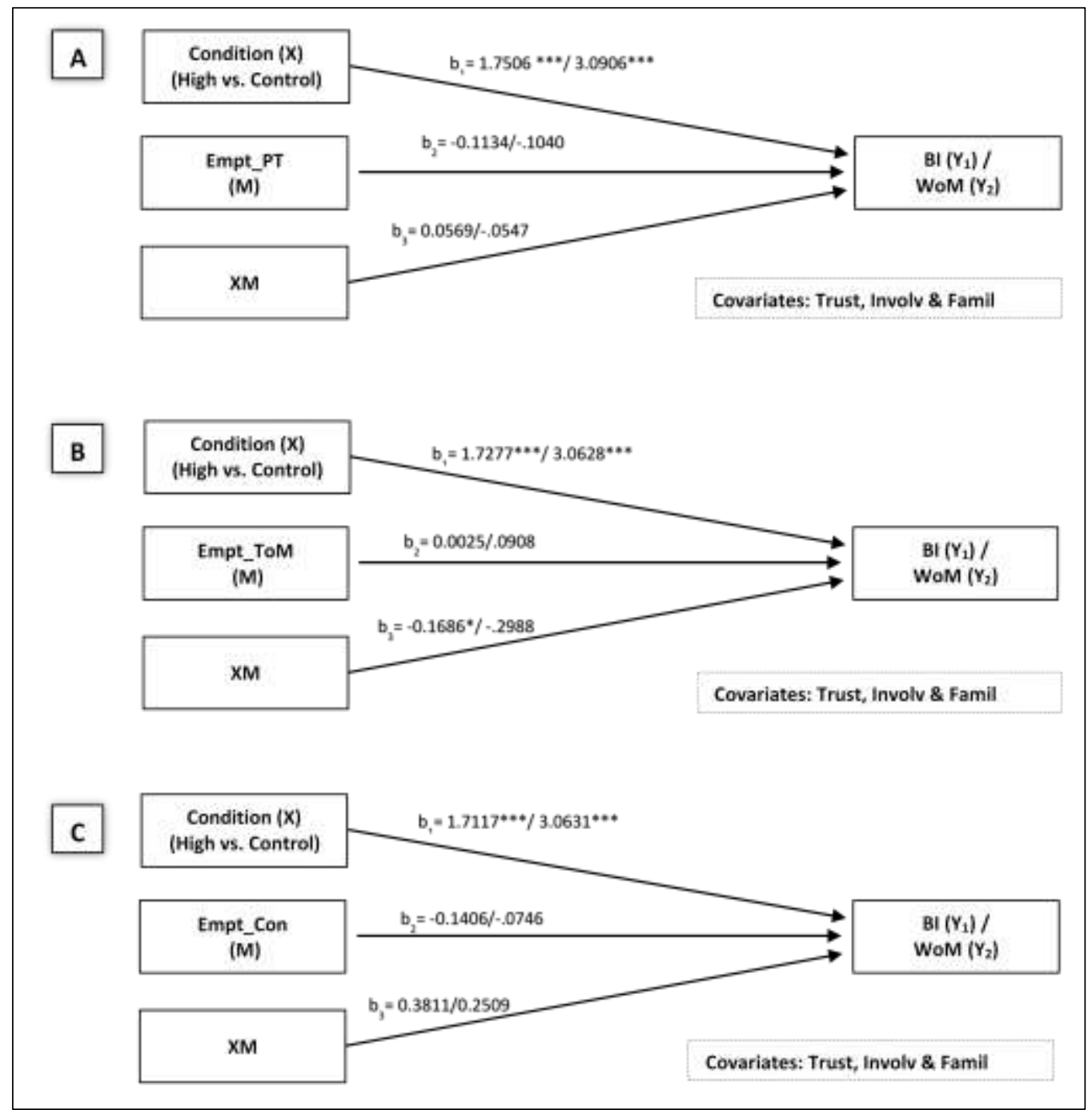

Table 2 Regression Coefficients, Standard Errors and Model Summary for the Simple Moderation Models (Y1: BI) 


\section{جامية قانزة السويست - كلية التجارة إلسماعيلية}

Consumer Participation in Co-creation: Investigating the

Reem Refai Ahmed Mahmoud

\begin{tabular}{|c|c|c|c|c|}
\hline \multicolumn{5}{|c|}{ Empathy } \\
\hline Model 3.1 & b & $\mathrm{SE}$ & $\mathrm{t}$ & $\mathrm{p}$ \\
\hline $\mathrm{X} \rightarrow \mathrm{Y}_{1}(\mathrm{~b} 1)$ & 1.7506 & 0.2178 & 8.0392 & $<0.001$ \\
\hline $\mathrm{M}_{1} \rightarrow \mathrm{Y}_{1}(\mathrm{~b} 2)$ & -0.1134 & 0.1336 & -0.849 & 0.3980 \\
\hline $\mathrm{X}^{*} \mathrm{M}_{1} \rightarrow \mathrm{Y}_{1}(\mathrm{~b} 3)$ & 0.0569 & 0.2664 & 0.2138 & 0.8312 \\
\hline Overall model: & \multicolumn{4}{|c|}{$R^{2}=.5057, M S E=1.0428, F(6,96)=16.370, p<.001$} \\
\hline Model 3.2 & b & SE & t & p \\
\hline $\mathrm{X} \rightarrow \mathrm{Y}_{1}(\mathrm{~b} 1)$ & 1.7277 & 0.2172 & 7.9538 & $<.001$ \\
\hline $\mathrm{M}_{2} \rightarrow \mathrm{Y}_{1}(\mathrm{~b} 2)$ & 0.0025 & 0.1274 & 0.0196 & 0.9844 \\
\hline $\mathrm{X}^{*} \mathrm{M}_{2} \rightarrow \mathrm{Y}_{1(\mathrm{~b} 3)}$ & -0.1686 & 0.2559 & 0.6589 & 0.5115 \\
\hline Overall model: & \multicolumn{4}{|c|}{$R^{2}=.5038, M S E=1.0467, F(6,96)=16.2477, p<.001$} \\
\hline Model 3.3 & b & SE & $\mathbf{t}$ & $\mathbf{p}$ \\
\hline $\mathrm{X} \rightarrow \mathrm{M}_{3}(\mathrm{~b} 1)$ & 1.7117 & 0.2139 & 8.003 & $<.001$ \\
\hline $\mathrm{M}_{3} \rightarrow \mathrm{Y}_{1}(\mathrm{~b} 2)$ & -0.1406 & 0.1291 & -1.0888 & 0.279 \\
\hline $\mathrm{X}^{*} \mathrm{M}_{3} \rightarrow \mathrm{Y}_{1(\mathrm{~b} 3)}$ & 0.3811 & 0.2466 & 1.545 & 0.1256 \\
\hline Overall model: & \multicolumn{4}{|c|}{$R^{2}=.5207, M S E=1.0111, F(6,96)=17.3826, p<.001$} \\
\hline
\end{tabular}

Table 3 Regression Coefficients, Standard Errors and Mode1 Summary for the Simple Moderation Mode1s (Y1: WoM)

\begin{tabular}{|c|c|c|c|c|}
\hline \multicolumn{5}{|c|}{ Empathy } \\
\hline Model 4.1 & b & SE & $\mathrm{t}$ & $\mathrm{p}$ \\
\hline $\mathrm{X} \rightarrow \mathrm{Y}_{1}(\mathrm{~b} 1)$ & 3.0906 & 0.2847 & 10.8575 & $<0.001$ \\
\hline
\end{tabular}




\section{جامية قانزة السويست - كلية التجارة إلسماعيلية}

Consumer Participation in Co-creation: Investigating the

Reem Refai Ahmed Mahmoud

\begin{tabular}{|c|c|c|c|c|}
\hline $\mathrm{M}_{1} \rightarrow \mathrm{Y}_{1}(\mathrm{~b} 2)$ & -.1040 & 0.1746 & -0.5958 & .5527 \\
\hline $\mathrm{X}^{*} \mathrm{M}_{1} \rightarrow \mathrm{Y}_{1}(\mathrm{~b} 3)$ & -.0547 & .3482 & -.1572 & .8754 \\
\hline Overall model: & \multicolumn{4}{|c|}{$R^{2}=.6282, M S E=1.7818, F(6,96)=27.0372, p<.001$} \\
\hline Model 4.2 & b & SE & $\mathrm{t}$ & $\mathbf{p}$ \\
\hline $\mathrm{X} \rightarrow \mathrm{Y}_{2}(\mathrm{~b} 1)$ & 3.0628 & .2822 & 10.8526 & $<.001$ \\
\hline $\mathrm{M}_{2} \rightarrow \mathrm{Y}_{1}(\mathrm{~b} 2)$ & .0908 & .1656 & .5486 & .5846 \\
\hline $\mathrm{X}^{*} \mathrm{M}_{2} \rightarrow \mathrm{Y}_{1(\mathrm{~b} 3)}$ & -.2988 & .3325 & -.8984 & .3712 \\
\hline Overall model: & \multicolumn{4}{|c|}{$R^{2}=.6313, M S E=1.7669, F(6,96)=27.4008, p<.001$} \\
\hline Model 4.3 & b & SE & $\mathbf{t}$ & $\mathbf{p}$ \\
\hline $\mathrm{X} \rightarrow \mathrm{M}_{3}(\mathrm{~b} 1)$ & 3.0631 & 0.2832 & 10.8150 & $<.001$ \\
\hline $\mathrm{M}_{3} \rightarrow \mathrm{Y}_{1}(\mathrm{~b} 2)$ & -.0746 & 0.1710 & -0.4362 & .6637 \\
\hline $\mathrm{X}^{*} \mathrm{M}_{3} \rightarrow \mathrm{Y}_{1}(\mathrm{~b} 3)$ & 0.2509 & 0.3266 & 0.7681 & .4443 \\
\hline Overall model: & \multicolumn{4}{|c|}{$R^{2}=.6300, M S E=1.7732, F(6,96)=27.2454, p<.001$} \\
\hline
\end{tabular}

\section{Discussion \& Conclusion}

Our study tries to investigate under what conditions cocreation leads to these behavioral outcomes. We then proposed empathy as a moderator variable that represent one of these conditions. We assumed that the impact of cocreation on behavioral intentions and word of mouth communication intentions is conditional on levels of empathetic orientations. 
Consumer Participation in Co-creation: Investigating the

Reem Refai Ahmed Mahmoud

The finding did not provide support for any of the empathy subscales as a moderator of the link between cocreation on both behavioral intentions and word of mouth communication intentions. The interaction term was not significant for each of them. Thus, regardless of the level of empathetic orientation an individual co-creation produces a positively strong direct impact on both behavioral intentions and word of mouth communication intentions. These findings fail to support prior research (see for example, Bharti, Agrawal, and Sharma, 2014), indicating that empathy is an important factor in influencing customers to participate in value co-creation activities. Particularly, empathetic attitudes of consumers toward the cause or community might influence the participation decision. Prior research, however, was conceptual and speculative, and did not test this link empirically, as in our current study. Another potential reason for lack of support is that the outcomes of type of co-creation described in the experimental scenarios are personal and do not clearly have direct spill over impact on the whole community. Thus, in our case the argued impact of empathy might not be applicable. Future research should consider testing this link on different types of co-creation (e.g., cocreation for others) to provide deeper understanding on the role of empathy. 
Consumer Participation in Co-creation: Investigating the

Reem Refai Ahmed Mahmoud

\section{Limitations and Future Research}

As with most studies, this research has some limitations. The current study outcome variables were likelihood of actions and intention to act as proxy measures for actual behavior. Thus, it has unknown validity in precisely determining the effects of co-creation on actual behavior of consumers. Still, to the degree that the behavioral intentions we did measure are meaningful, we would claim that our current study offers plausibly the most valid and valuable findings until now concerning customers' co-creation experiences. Indeed few studies have empirically tested cocreation, and few studies have used strong theoretical and comprehensive models.

The above-mentioned limitation represents a departure point for future academic research to advance our understanding regarding customer's co-creation experiences, its antecedences and boundary conditions. 


\section{References}

Bagozzi, R. P., \& Dholakia, U. M. (2006). Antecedents and purchase consequences of customer participation in small group brand communities. International Journal of research in Marketing, 23(1), 4561.

Bagozzi, R. P., \& Moore, D. J. (1994). Public service advertisements: Emotions and empathy guide prosocial behavior. The Journal of Marketing, 56-70.

Baron-Cohen, S., \& Wheelwright, S. (2004). The empathy quotient: an investigation of adults with Asperger syndrome or high functioning autism, and normal sex differences. Journal of autism and developmental disorders, 34(2), 163-175.

Bharti, K., Agrawal, R., \& Sharma, V. (2014). What drives the customer of world's largest market to participate in value co-creation? Marketing Intelligence \& Planning, 32(4), 413-435.

Chuang, H. M., \& Chen, Y. S. (2015). Identifying the value co-creation behavior of virtual customer environments using a hybrid expert-based DANP model in the bicycle industry. Human-centric Computing and Information Sciences, 5(1), 1.

Davis, M. H. (1980). A multidimensional approach to individual differences in empathy.

Delgado-Ballester, E., \& Luis Munuera-Alemán, J. (2001). Brand trust in the context of consumer loyalty. European Journal of marketing, 35(11/12), $1238-1258$.

Edvardsson, B., Gustafsson, A., Kristensson, P., \& Witell, L. (2010). Service Innovation service innovation and Customer Co-development. In Handbook of service science (pp. 561-577). Springer US. 
Gustafsson, A., Kristensson, P., \& Witell, L. (2012). Customer co-creation in service innovation: a matter of communication?. Journal of Service Management, 23(3), 311-327.

Hoyer, W. D., Chandy, R., Dorotic, M., Krafft, M., \& Singh, S. S. (2010). Consumer cocreation in new product development. Journal of Service Research, 13(3), 283-296

Kambil, A., Ginsberg, A., \& Bloch, M. (1996). Re-inventing value propositions. Information Systems Working Papers Series, Vol.

Mahmoud, R.R.A. (This Issue), Utility of the theory of planned behavior for predicting consumers' intentions toward involvement in co-creation activities.

Prahalad, C. K., \& Ramaswamy, V. (2004). The future of competition. Harvard Business School Press, Boston, MA

Ramaswamy, V., \& Gouillart, F. J. (2010b). The power of co-creation: Build it with them to boost growth, productivity, and profits. Simon and Schuster

Roberts, D., Hughes, M., \& Kertbo, K. (2014). Exploring consumers' motivations to engage in innovation through co-creation activities. European Journal of Marketing, 48(1/2), 147-169

Rosenbaum, M. S., \& Massiah, C. A. (2007). When customers receive support from other customers: Exploring the influence of intercustomer social support on customer voluntary performance. Journal of Service Research, 9(3), 257-270.

Witell, L., Kristensson, P., Gustafsson, A., \& Löfgren, M. (2011). Idea generation: customer co-creation versus traditional market research techniques. Journal of Service Management, 22(2), 140-159.

Zwass, V. (2010). Co-creation: Toward a taxonomy and an integrated research perspective. International Journal of Electronic Commerce, 15(1), 11-48. 